\title{
Effects of latanoprost and dipivefrin, alone or combined, on intraocular pressure and on blood-aqueous barrier permeability
}

\author{
I Widengård, O Mäepea, A Alm
}

\begin{abstract}
Aim-To investigate the effect on intraocular pressure (IOP) and aqueous flare of topical applications of latanoprost and dipivefrin alone or combined.

Methods-22 patients with open angle glaucoma or ocular hypertension were included in a 4 week open label study. Median age was 68 years (range 50-79). They were allocated to either 2 weeks' treatment with once daily evening administration of latanoprost monotherapy (50 $\mu \mathrm{g} / \mathrm{ml}$ ) or twice daily dipivefrin monotherapy ( $1 \mathrm{mg} / \mathrm{ml})$, followed by 2 weeks' combination therapy with both drugs.

Results-Latanoprost alone reduced IOP from 19.3 (SD 1.4) to $14.8(0.9) \mathrm{mm} \mathrm{Hg}$ $(p<0.01)$. Addition of dipivefrin caused a further reduction to $12.4(0.9) \mathrm{mm} \mathrm{Hg}$ $(p<0.01$ compared with latanoprost alone). In the group where the treatment started with dipivefrin IOP was reduced from $22.3(1.2)$ to $18.4(1.0) \mathrm{mm} \mathrm{Hg}$ $(p<0.01)$ and with the combination to 14.9 $(0.9) \mathrm{mm} \mathrm{Hg}(\mathrm{p}<0.01)$. No change in aqueous flare was observed with either drug, alone or in combination. A slight increase in conjunctival hyperaemia was observed when the two drugs were combined.

Conclusions-Latanoprost and dipivefrin have an additive effect on IOP and no clinically significant effect on the permeability to proteins of the blood-aqueous barrier. This implies that the two drugs can be a useful combination for the treatment of glaucoma.

(Br F Ophthalmol 1998;82:404-406)
\end{abstract}

Latanoprost, a prostaglandin $\mathrm{F}_{2 \alpha}$ analogue $\mathrm{e}^{2}$ has recently been introduced as an ocular hypotensive agent. Recent large studies have shown it to be a potent agent in patients with glaucoma or ocular hypertension. ${ }^{3-6}$ It has also been suggested that the ocular hypotensive effect of adrenaline may be at least partly mediated by an endogenous production of prostaglandins. $^{78}$ Thus, both from a theoretical and a clinical point of view it would be of interest to determine the effect on intraocular pressure (IOP) of the combination of a prostaglandin analogue and an adrenergic agonist.

A further reason to study this combination is the possibility that the two drugs combined could have an effect on the permeability of the blood-aqueous barrier. In the rabbit low doses of naturally occurring prostaglandins reduce
IOP while high doses cause an increased IOP with a breakdown of the blood-aqueous barrier. ${ }^{9}$ The eyes of cats and monkeys are much more resistant and a similar breakdown of the blood-aqueous barrier was not observed even after repeated topical application of prostaglandins. ${ }^{10}$ In previous clinical studies latanoprost monotherapy had no effect on aqueous flare. ${ }^{112}$ Adrenergic agonists may also affect the permeability of the blood-aqueous barrier. Thus chronic stimulation of the sympathetic nerves in rabbits causes a breakdown of the blood-aqueous barrier that seems to be mediated by prostaglandins. ${ }^{13} \mathrm{~A}$ small prostaglandin mediated increase in the bloodaqueous barrier permeability to sodium fluorescein was reported after treatment with adrenaline for 2 months or more in human eyes, ${ }^{14}$ and Araie et al reported a biphasic response of the blood-aqueous barrier in human eyes to a single dose of phenylephrine; an initial marked increase in aqueous flare followed by a decrease. ${ }^{15}$ The present study was performed to evaluate the effect of latanoprost and dipivefrin, either individually or in combination, on IOP and on the blood-aqueous barrier in patients with open angle glaucoma or ocular hypertension.

Materials and methods

This was a 4 week open label randomised study. The study protocol was approved by the Swedish regulatory authority and the local ethics committee. The study was performed in accordance with the revised Declaration of Helsinki (Hong Kong 1989). Each patient gave written informed consent before entry into the study.

Patients with unilateral or bilateral open angle glaucoma, capsular glaucoma, or ocular hypertension (a prestudy IOP of at least 22 $\mathrm{mm} \mathrm{Hg}$ ) were included. If both eyes fulfilled the eligibility criteria, the right eye was designated as the study eye. There was a washout period of previous treatment in the study eye of 2 weeks for adrenergic agonists, 5 days for cholinergic agonists or oral carbonic anhydrase inhibitors, and 3 weeks for $\beta$ adrenergic blockers.

Exclusion criteria included an IOP of $>35$ $\mathrm{mm} \mathrm{Hg}$ on current treatment, concomitant medication known to affect IOP, pregnancy, a history of acute angle closure, or severe dry eye syndrome, intraocular surgery or argon laser trabeculoplasty within the previous 6 months, current use of contact lenses, ocular inflammation/infection within the previous 15
Accepted for publication 5 November 1997 
Table 1 Patient demographics

\begin{tabular}{llll}
\hline & Lat/Dip & Dip/Latt & All \\
\hline Mean age (range) & $69(50-79)$ & $68(60-74)$ & $68(50-79)$ \\
Sex (M/F) & $8 / 3$ & $7 / 4$ & $15 / 7$ \\
Diagnosis & 8 & 4 & 12 \\
$\quad$ POAG & 1 & 3 & 4 \\
Capsular glaucoma & 2 & 4 & 6 \\
OH & 11 & 9 & 20 \\
Previous glaucoma treatment & & 9 & \\
\hline
\end{tabular}

${ }^{\star}$ Group that started with latanoprost with dipivefrin added after 2 weeks' treatment. †Treatment was initiated with dipivefrin.

Table 2 IOP (mean (SEM)) at baseline and after 2, 3, and 4 weeks' treatment for patients who started treatment with latanoprost (Lat/Dip) or dipivefrin (Dip/Lat)

\begin{tabular}{lllll}
\hline Treatment & Day 0 & Day 14 & Day 21 & Day 28 \\
\hline Lat/Dip & $19.3(1.4)$ & $14.8(0.9)$ & $12.1(0.9)$ & $12.4(0.9)$ \\
Dip/Lat & $22.3(1.2)$ & $18.4(1.0)$ & $13.2(0.7)$ & $14.9(0.9)$ \\
\hline
\end{tabular}

Table 3 Aqueous flare as photon counts (mean (SEM)) at baseline and after 2, 3, and 4 weeks' treatment for patients who started treatment with latanoprost (Lat/Dip) or dipivefrin (Dip/Lat)

\begin{tabular}{lllll}
\hline Treatment & Day 0 & Day 14 & Day 21 & Day 28 \\
\hline Lat/Dip & $10.4(1.1)$ & $8.6(1.0)$ & $9.8(1.1)$ & $9.6(1.3)$ \\
Dip/Lat & $7.4(1.1)$ & $7.2(0.8)$ & $7.4(0.9)$ & $7.2(0.6)$ \\
\hline
\end{tabular}

Table 4 Hyperaemia score (mean (SEM)) obtained by comparing with a set of standard photographs from none (0) to severe (3) at baseline and after 2, 3, and 4 weeks' treatment for patients who started treatment with latanoprost (Lat/Dip) or dipivefrin (Dip/Lat)

\begin{tabular}{lllll}
\hline Treatment & Day 0 & Day 14 & Day 21 & Day 28 \\
\hline Lat/Dip & $0.59(0.12)$ & $0.64(0.14)$ & $0.95(0.16)$ & $1.00(0.20)$ \\
Dip/Lat & $0.45(0.13)$ & $0.59(0.16)$ & $1.00(0.18)$ & $1.18(0.19)$ \\
\hline
\end{tabular}

months, and any condition preventing reliable applanation tonometry.

The study comprised five visits; a prestudy evaluation within 1 month of study start followed by randomisation to treatment at baseline (day 0), and evaluations on days 14, 21 , and 28. After randomisation, patients were allocated to treatment with 2 weeks of monotherapy with latanoprost or dipivefrin, followed by 2 weeks of combined therapy with both drugs. Latanoprost $50 \mu \mathrm{g} / \mathrm{ml}$ was administered once daily in the evening ( $9 \mathrm{pm})$. Dipivefrin (dipivalyl adrenaline) $1 \mathrm{mg} / \mathrm{ml}$ was administered in the morning (9 am) and in the evening $(9 \mathrm{pm})$. During combined therapy, patients were instructed to instil the two eyedrops 5 minutes apart.

IOP was determined with a Goldmann tonometer at $9 \mathrm{am}$. The mean of three consecutive readings was used for analysis. Flare was determined with the Kowa laser flare meter (Kowa FM500). Ten readings were made, the highest and the lowest values were discarded and the mean of the remaining eight values was used for analysis. Evaluation of conjunctival hyperaemia (none $=0$, mild $=1$, moderate $=2$, severe $=3$ ) was performed using standard photographs. Routine clinical examinations of the eyes, including determination of visual acuity and refraction, slit lamp examination, and ophthalmoscopy were performed at each visit. All examinations were performed before applying the next dose at 9 am, 12 hours after the previous dose. To avoid optical interference caused by the application of fluorescein and the tonometer probe, flare was measured before IOP.
STATISTICAL ANALYSIS

Statistical significance of changes in IOP and flare between each examination was evaluated with the paired $t$ test within the treatment groups and with the $t$ test between the treatment groups. Mean (SEM) are presented. The change in hyperaemia score between each examination was tested with the sign test within the treatment groups, and with the Wilcoxon rank sum test between the two treatment groups. All statistical tests were performed at the $5 \%$ level.

\section{Results}

Twenty two patients were included in the study, all of whom completed the 4 week treatment period. The demographic characteristics of the study population are shown in Table 1. In general, there were no major differences in patient characteristics between the two treatment groups. Even though the patients were assigned randomly there was a difference in IOP at baseline (day 0) between treatment groups of $3 \mathrm{~mm} \mathrm{Hg}$.

Table 2 presents the IOP for each examination in the two treatment groups. Latanoprost alone reduced morning IOP with 4.5 (1.2) $\mathrm{mm}$ $\mathrm{Hg}(\mathrm{p}<0.01)$ from $19.3 \mathrm{~mm} \mathrm{Hg}$. Adding dipivefrin caused a further reduction of 2.3 (0.6) $\mathrm{mm} \mathrm{Hg}$ on day 28 ( $\mathrm{p}<0.01)$. Combined, the two drugs reduced IOP with $6.9 \mathrm{~mm} \mathrm{Hg}$ $(35 \%, \mathrm{p}<0.0001)$ on day 28 .

Dipivefrin alone reduced morning IOP with 3.9 (1.1) $\mathrm{mm} \mathrm{Hg}(\mathrm{p}<0.01)$ from $22.3 \mathrm{~mm} \mathrm{Hg}$. Adding latanoprost caused a further reduction of $3.6(0.5) \mathrm{mm} \mathrm{Hg}$ on day $28(\mathrm{p}<0.0001)$. In this group the two drugs combined caused an IOP reduction from baseline of $7.4 \mathrm{~mm} \mathrm{Hg}$ $(33 \%, \mathrm{p}<0.0001)$.

Table 3 presents photon count values. In each group the highest mean values were observed on baseline and neither drug, alone or combined, caused a significant change in flare values. Compared with baseline, flare values on day 28 were increased in seven patients, unchanged in two, and decreased in 13 patients with a range from an increase of 6.5 photon counts to a reduction of 7.1 . In addition, slit lamp evaluation of flare and cells revealed no clinically significant effects of treatment.

Hyperaemia scores are presented in Table 4. At baseline mean hyperaemia was graded between none and mild, and no change occurred when either drug was applied alone. With the two drugs combined the hyperaemia score almost doubled $(p<0.05)$, but the average hyperaemia was still judged to be mild. Moderate hyperaemia, grade 2, was observed in five of 22 patients on the last examination.

No change in refraction or visual acuity was observed. Mild punctate corneal erosions were observed in two eyes on day 28; one untreated eye and one that had been treated with dipivefrin for 4 weeks with latanoprost added for the last 2 weeks.

\section{Discussion}

A majority of the patients included in this study had a diagnosis of open angle glaucoma. 
There was no lower IOP limit for inclusion of patients with established glaucoma, and the mean baseline IOP in the two groups was only 19 and $22 \mathrm{~mm} \mathrm{Hg}$ respectively. One can expect less effect on IOP, both in absolute and relative terms, with a low initial IOP. Still, both latanoprost and dipivefrin caused statistically highly significant reductions in IOP when applied alone. Moreover, a statistically significant further reduction in IOP was observed when the two drugs were combined for the last 14 days of the study with an added reduction of $16 \%$ for dipivefrin and $19 \%$ for latanoprost. These results do not indicate that a possible prostaglandin mediated effect of adrenaline, as reported by Camras et al, ${ }^{7}$ diminishes the effect of latanoprost. A solution of $50 \mu \mathrm{g} / \mathrm{ml}$ is at the top of the dose-response curve for latanoprost. ${ }^{16}$ Prostaglandin effects are mediated by a family of receptors and latanoprost is a rather selective agonist for one of them, the FP receptor. ${ }^{1}$ Thus, in the event that prostaglandin receptors are involved in the ocular hypotensive effect of adrenaline one may speculate that other prostaglandin receptors than the FP receptor are involved.

An additive effect of $19 \%$ when latanoprost is added to dipivefrin is of clinical interest since the number of clinically useful combinations including dipivefrin is limited; a reduction of IOP of $20 \%$ or more can mainly be expected by adding a full dose of acetazolamide, judged from early experience of combining adrenaline and acetazolamide. ${ }^{17}$ The effect of adding dipivefrin to timolol results, as expected, in only a small or no additive effect on IOP, ${ }^{18}{ }^{19}$ while combining dipivefrin and pilocarpine can only be expected to give a modest additive effect; the effect of combining $2 \%$ pilocarpine and $1 \%$ adrenaline resulted in an IOP that was $12 \%$ lower than with pilocarpine alone. ${ }^{20}$

Neither latanoprost nor dipivefrin, alone or combined, caused any increase in flare as evaluated with the laser flare meter. Previous studies with quantitative evaluation of flare have not shown any effect for either latanoprost ${ }^{11}{ }^{12}$ or adrenaline, ${ }^{21}$ but a slight increase in the permeability of the bloodaqueous barrier to fluorescein was reported after 2 months' treatment with adrenaline in human eyes. ${ }^{12}$ This effect seemed to be mediated by prostaglandins since it was prevented by indomethacin. Fluorescein is a small molecule that normally passes through the blood-aqueous barrier slowly and the change in the barrier permeability necessary to cause a slight increase in fluorescein permeation is probably of no clinical relevance. It is also unlikely that the effect is mediated by the FP receptor. In rabbits prostaglandin induced breakdown of the blood-aqueous barrier occurs mainly with agents that have a high affinity for the $\mathrm{EP}_{2}$ receptor, and $\mathrm{FP}$ receptor agonists do not disrupt the barrier. ${ }^{22}$ As latanoprost has little or no affinity for the $\mathrm{EP}_{2}$ receptor $^{1}$ it is not surprising that we found no effect on aqueous flare.

Both latanoprost and dipivefrin were very well tolerated either alone or in combination. A slight increase in conjunctival hyperaemia was observed in some patients following combination treatment. However, this was mild and did not require the cessation of treatment.

In conclusion, both latanoprost and dipivefrin reduced IOP effectively in patients with open angle glaucoma or ocular hypertension. Whether given alone or in combination they had no measurable effect on the permeability of the blood-aqueous barrier to proteins. Moreover, the combination of latanoprost and dipivefrin had an additive effect on IOP reduction and was well tolerated. This implies that the combination of latanoprost and dipivefrin should prove an effective and safe addition to the current treatment options for glaucoma.

1 Stjernschantz J, Resul B. Phenyl-substituted prostaglandin analogs for glaucoma treatment. Drugs Future 1992; 17:691-704.

2 Resul B, Stjernschantz J, No K, et al. Phenyl-substituted prostaglandins: potent and selective antiglaucoma agents. f Med Chem 1993;36:243-8.

3 Alm A, Stjernschantz J, the Swedish Latanoprost Study Group. Effects on intraocular pressure and side effects of $0.005 \%$ latanoprost applied once daily evening or morning. A comparison with timolol. Ophthalmology 1995;102:174352 .

4 Camras CB, the United States Latanoprost Study Group. Comparison of latanoprost and timolol in patients with ocular hypertension and glaucoma. A six-month, masked, multicenter trial in the United States. Ophthalmology 1996; 103:138-47.

5 Watson P, Stjernschantz J, the Latanoprost Study Group. A six-month randomised, double-masked study comparing
latanoprost with timolol in open-angle glaucoma and ocular hypertension. Ophthalmology 1996;103:126-37.

6 Mishima HK, Masuda K, Kitazawa Y, Azuma I, Araie M. A comparison of latanoprost and timolol in primary openangle glaucoma and ocular hypertension. A 12 week study. Arch Ophthalmol 1996;114:929-32.

7 Camras CB, Feldman SG, Podos SM, et al. Inhibitors of the epinephrine-induced reduction of intraocular pressure by epinephrine-induced reduction of intraocular pressure by
systemic indomethacin in humans. Am f Ophthalmol 1985; 100:169-75.

8 Anderson L, Wilson WS. Inhibition of indomethacin of the increased facility of outflow induced by adrenaline. Exp Eye Res 1990;50:119-26.

9 Camras CB, Bito LZ, Eakins KE. Reduction of intraocular pressure by prostaglandins applied topically to the eyes of conscious rabbits. Invest Ophthalmol Vis Sci 1977;16:112534.

10 Bito LZ, Draga A, Blanco J, Camras CB. Long-term maintenance of reduced intraocular pressure by daily or twice daily topical application of prostaglandins to cat or rhesus monkey eyes. Invest Ophthalmol Vis Sci 1983;24:312-9.

11 Ziai N, Dolan JW, Kacere RD, Brubaker RF. The effects on aqueous dynamics of PhXA41, a new prostaglandin $\mathrm{F}_{2}$ analogue, after topical application in normal and ocular hypertensive human eyes. Arch Ophthalmol 1993;111: $1351-8$

12 Hotehama Y, Mishima HK. Clinical efficacy of PhXA34 and PhXA41, two novel prostaglandin $\mathrm{F}_{2 \alpha}$-isopropyl ester analogues for glaucoma treatment. $\mathcal{F} n$ F O Ophthalmol 1993; 37:259-69

13 Bartels SP, Pawlowski AM. Chronic electrical stimulation of sympathetic nerves: effects on blood-aqueous barrier. Curr Eye Res 1990;9:927-34.

14 Miyake K, Miyake Y, Kuratomi R. Long-term effects of topically applied epinephrine on the blood-aqueous barrier in humans. Arch Ophthalmol 1987;105:1360-63.

15 Araie M, Mori M, Oshika T. Effect of topical phenylephrine on the permeability of the blood-aqueous barrier in man. Graefes Arch Clin Exp Ophthalmol 1992;230:171-4.

16 Alm A, Villumsen J, Tornquist P, et al. Intraocular pressure reducing effect of PhXA41 in ocular hypertensive agents-a one-month study. Ophthalmology 1993;100: agents-

17 Becker B. Additive effect of epinephrine and acetazolamide in control of intraocular pressure. Am $\mathcal{f}$ Ophthalmol 1958;75:639-42

18 Parrow KA, Hong YJ, Shin DH, Shi DX, McCarty B. Is it worthwhile to add dipivefrin $\mathrm{HCl} 0.1 \%$ to topical beta-1-, beta-2-blocker therapy? Ophthalmology 1989;96:1338-42.

19 Morrison JC, Robin AL. Adjunctive glaucoma therapy. A comparison of apraclonidine to dipivefrin when added to timolol maleate. Ophthalmology 1989;96:3-7.

20 Brounley DW. A comparison of pilocarpine hydrochloride and epinehrine bitartrate. Ann Ophthalmol 1971;3:970-3.

21 Mori M, Sakurai M, Araie M. Effect of topical epinephrine on permeability of blood-aqueous barrier in human eyes. on perm Ophthalmol 1992;36:342-7.

22 Protzman CE, Woodward DF. Prostanoid-induced bloodaqueous barrier breakdown in rabbits involves the $\mathrm{EP}_{2}$ receptor subtype. Invest Ophthalmol Vis Sci 1990;31:24636. 